\title{
1. Introduction: how to be a reflexive researcher
}

My father was shouting at my mother, after coming home drunk, as I stepped into the room. I was seven years old and frightened. I started to cry. That was the first time my father called me a "fucking little queer".

As time passed fear turned to hate; I learned to loathe everything about him. I noticed his rolling macho gait... and made sure I walked in a very upright way. Hearing his noisy breathing when he was drunk and asleep in an armchair, I monitored my breathing to make sure it was inaudible. He was a prodigious drinker and was foul-mouthed - before I left the family home when I was eighteen, I refused to either drink or swear. This confused my few friends in the last couple of years at high school, most of whom would somehow smuggle the occasional beer here or there... and away from class their language was pretty unrestrained. It took me a long time to loosen up.

\subsection{REFLEXIVITY IS A PERSONAL PROJECT}

There are lots of ways of looking at reflexivity, but for me it is at heart a personal project. We all change in response to experience (even if it is not always as extreme a reaction as described in the autobiographical excerpt above) and that is the essence of reflexivity. It is a process of engaging with experience, that changes our ways of understanding and guides adaptation in readiness for future experiences. This has implications for our everyday life, but also for the understandings on which interpretive research processes are built. With that in mind I used the brief autobiographical except above above as an illustration because it shows how changing in response to experience can include four levels, even in relation to one small event:

- Embodied (my seven-year-old self amongst adults)

- Emotional (fear and crying)

- Rational (decisions about undesirable behaviours like drinking)

- Relational (interactions with my father, mother and friends).

These are important insights for reflexive practice in research, which I will develop in detail later in this book.

Looking back there are other things, that I could not have known, that follow from my response to the experience narrated above. I would certainly not have 
characterised them as an example of reflexivity, for a start - that is not in the vocabulary of the average schoolkid. I was also unaware of all the effects that would flow from my choices, as well as being far less aware of less dramatic influences on how I changed as I grew up - the encouragement from particular teachers, my mother working hard to keep us all going, enthusiasms developed from reading. However, my main point here is not to dwell any further on my personal life, but instead - hopefully - to provide some resonance with your own experiences and responses, in order to emphasise the ordinariness and universality of reflexivity. This means that when we seek to become a reflexive researcher, there is a lot that we may be able to build on, but also quite a lot to unpack.

In academic conversations about reflexivity in research, we are often concerned to do one of two things. One alternative is to try to compensate for the 'skew' in our perspective, that causes us to see things in a certain individual way that may be atypical; for example, think of my teenage schoolfriends' bewilderment of my refusal to indulge in the occasional smuggled beer. Another alternative is to try to speak authentically from our experience; for example, I might be able to speak and write about angry and abusive fathers, in a way that others might find meaningful. Either of these alternatives is a possible way of being a reflexive researcher, especially if you are working within or from the interpretive tradition. With that in mind, the main purposes of this book are to set out the academic debates behind each position, develop a picture of reflexive practice that enables either approach to be adopted, and consider the issues and implications that follow from each approach. In the remainder of this introductory chapter, I outline how the book is arranged in order to fulfil those objectives. It is likely that the outline will raise questions that the detailed chapters that follow will answer.

\subsection{ENGAGING WITH THE FIELD: THE ACADEMIC PROJECT}

In the text above I have emphasised how reflexivity is a personal project. However, much of the literature in the field is concerned with the 'academic project' and how reflexivity is used in the service of our research. This is an important topic for all qualitative researchers and interpretive researchers in particular, who are called to account for the personal and intellectual means by which they develop their insights (Schwartz-Shea \& Yanow, 2012).

Chapter 2 explains how reflexivity is approached in the literature in a number of ways, largely focussed around four themes. Self-reflexivity focusses on the everyday processes of individual adaptation that are guided by our interpretation of experience (Archer, 2007; Caetano, 2017; Hibbert, Coupland \& MacIntosh, 2010; Hibbert, Beech \& Siedlok, 2017). Critical reflexivity seeks 
to identify the social constructions of tradition and ideology that shape our interpretations of experience, to interrupt and challenge the unquestioned norms that we carry and reproduce in this way (Aronowitz, Deener, Keene, Schnittker \& Tach, 2015; Hibbert, Beech \& Siedlok, 2017; Hibbert, Coupland \& MacIntosh, 2010; Hibbert \& Huxham, 2010, 2011). Relational reflexivity considers the interdependence of individuals in social contexts, the ways in which our thinking is shaped by the influence and insights of others, and how we influence them in turn (Hibbert, Sillince, Diefenbach \& Cunliffe, 2014; Cutcher, Hardy, Riach \& Thomas, 2020). Radical reflexivity takes the principles of self and critical reflexivity to their ultimate conclusion by denying robust foundational truths or easily generalisable insights about how we live in and interpret the world, in favour of local, subjective explanations (Cunliffe, 2003). An additional (and somewhat implicit) theme is instrumental reflexivity, which provides a balance or contrast to radical reflexivity by using the principles of critical reflexivity in a constrained and focussed approach, to remove less robust or persuasive insights about how we live in and interpret the world (Alvesson, Hardy \& Harley, 2008; Weick, 1999).

Chapter 2 goes on to show how the ways in which reflexivity can be described and enacted, as described above and applied most often in interpretive research, can also be gathered into two broader categories. The first category emerges through considering the example of ethnographic and autoethnographic research approaches. Such approaches depend (in part) on capturing how reflexivity is used to shape our future, as we adapt to our way of being with our research participants in their environments and change our research practice accordingly (Beech, Hibbert, McInnes \& MacIntosh, 2009). These approaches bring together insights focussed on self-reflexivity and relational reflexivity (Archer, 2007; Cutcher, Hardy, Riach \& Thomas, 2020; Hibbert, Coupland \& MacIntosh, 2010; Hibbert, Sillince, Diefenbach $\&$ Cunliffe, 2014). These two forms integrate as future-oriented reflexivity, focussed on how we actively change and develop, in response to the ways that we interpret our experience of the world from moment to moment. In future-oriented reflexivity, changes in the researcher's ways of being and doing are the most important outcomes and sources of insight (Hibbert, Beech, Callagher \& Siedlok, 2021).

The second category, focussing on how interpretive researchers seek to use reflexivity to look back on research experiences, to challenge their interpretations, brings together insights focussed on instrumental reflexivity, critical reflexivity and radical reflexivity (Alvesson, Hardy \& Harley, 2008; Cunliffe, 2003; Weick, 1999). Taking these themes together brings a different process into view. Although these approaches have different philosophical commitments and limits, they are all concerned with looking below the surface assumptions of past experience, to see how social and historical contexts 
have shaped us and our interpretations without any deliberate action on our part (Cunliffe, 2004; Hibbert, Coupland \& MacIntosh, 2010). This kind of engagement with our interpretive and formative hinterland (Hibbert, Beech \& Siedlok, 2017) can be characterised as past-oriented reflexivity.

While Chapter 2 addresses the major themes in the literature and develops new categorisations, it does not dwell in detail on the philosophical and paradigmatic debates that are common in the field, for reasons that are set out later. There are other treatments available if your interest tends in that direction, but a detailed engagement with those debates is not necessary for the main purposes of this book to be fulfilled. Instead, the focus in Chapter 2 is to outline themes and categories that can provide an initial handle on what reflexivity may mean, and how we can understand the ways in which it can connect to research projects. In that way, Chapter 2 provides the groundwork for considering in more detail how reflexivity, as an intellectual objective, can be translated into reflexive practice.

\subsection{OUTLINING REFLEXIVE PRACTICES}

The characterisation of reflexive practices that flow from theoretical understandings is set out in Chapter 3. The discussion in that chapter connects to the categorisations of reflexivity developed in Chapter 2, but of necessity includes additional, interdisciplinary engagements in relation to some of the major themes. Some of these engagements step beyond the bounds of established debate and in the field.

Chapter 3 builds up a characterisation and discussion of four levels of (overlapping) reflexive practice, namely embodied, emotional, rational and relational. While it is possible to argue for a more holistic conceptualisation, or to integrate a point of view using one kind of reflexive practice as the key (for example, rational reflexive practice could be focussed on developing an account of experiences at the other levels - and often is), my argument is that it makes a practical difference to consider the levels individually in the first instance.

Embodied reflexive practice involves developing a focus on interoception (Hardy \& Hibbert, 2012; Tsakiris \& De Preester, 2019), the awareness we have of what is going on within our bodies, which has often been seen to be less relevant than external information (Leder, 2019). This is a complex and emergent area of biological and medical science and provides a different perspective from those that interpretivist scholars are generally familiar with. I encourage you not to reach for the 'incommensurability' shield, but instead to engage with the interesting insights that are being developed in this field. The research in this area is in fact highly relevant, leading to important insights in a number of areas, such as: a link between emotions and our interoceptive 
experiences (Berntson, Gianaros \& Tsakiris, 2019); the relationship between better interoceptive awareness and the regulation of our emotions (Critchley \& Harrison, 2013); links between aroused bodily states and interpretations of human interactions (Hardy \& Hibbert, 2012); our experience of the passage of time (Wittman \& Meissner, 2019); the connection between interoception and our sense of the outside world that influences the stability of our sense of self. All of these insights are obviously important for the study of reflexivity, bringing to light both how we adapt in response to external experiences in and through the responses of our bodies, as well as how our bodies can shape how we gather experiences in the first place. As discussed in Chapter 3, the theme of embodied reflexive practice also has a strong connection to the level of emotional reflexive practice and, in some ways, sets the stage for that.

Research has also begun to direct substantial attention towards emotion and reflexivity as an important theme in its own right, with some suggesting that emotions are the basis for reflexive thought and practice (Archer, 2007; Burkitt, 2012; Holmes, 2010). In addition, some specific areas of research in the social sciences are naturally and focally concerned with emotion, such as studies that look at dying and suffering (Evans, Ribbens McCarthy, Bowlby, Wouangoa \& Kébé, 2017; Miller, 2002), while most areas of human behaviour worthy of study in social and organisational contexts necessarily involve emotion on some level (Lindebaum, 2017). Emotions are, however, complex and entangled with physiological and cognitive processes (Immordino-Yang, 2016) and thus reflexive practice focussing on emotional perceptions can impact dramatically on how situations and possibilities for action are interpreted and understood (Brown \& de Graaf, 2013). Building on this, there are a range of specific ways in which emotions can be connected to reflexive practice, especially when the situation calls for some significant change in understanding and approach to action (Hibbert, Callagher, Siedlok, Windahl \& Kim, 2019) and there is also a strong link to debates about what is entailed in self-reflexivity in the context of remembered experiences (Corlett, 2013). Overall, the role of both negative and positive perceptions of emotion (Brown \& de Graaf, 2013; Hibbert, Beech, Callagher \& Siedlok, 2021; Shin, 2014) that can proceed rational thought are an essential focus for reflexive practice, and Chapter 3 focusses on emotional reflexive practice and attention to emotional perceptions in some detail.

The most familiar conceptualisations of reflexive practice are, however, concerned with rational thought. Indeed, rational reflexivity often encompasses what people mean by reflexivity as such, and can be imagined as a process of 'thinking about our thinking', to examine how and why we interpret things in the ways that we do (Hibbert, Coupland \& MacIntosh, 2010). Framed in that way, rational reflexive practice is a matter of choice in everyday life and especially in the situations of research, in which it can be mobilised 
selectively and deliberately and operationalised through specific frameworks or tools (Alvesson, Hardy \& Harley, 2008; Weick, 1999). However, approaches to rational reflexive practice may also have strong relational and/ or emotional overlaps too (Ripamonti, Galuppo, Gorli, Scaratti \& Cunliffe, 2017). However, all of the varieties of rational reflexive practice tend to be concerned with the same underlying focus, namely opening up our patterns of interpretation to critical examination in order to see the social, ideological and traditional influences in our formative past that have shaped them (Hibbert, Beech \& Siedlok, 2017; Hibbert \& Huxham, 2010, 2011; McLean, Harvey \& Chia, 2012; Sklaveniti \& Steyaert, 2020).

Rational reflexive practice always runs up against the problem of having no neutral place to stand from which to examine our own formation (Cunliffe, 2003; Hibbert, Coupland \& MacIntosh, 2010), meaning that our accounts are less transparent with regard to their influences and sources than we would like them to be. However, enhanced awareness of what is going on in the process of interpretation helps us to break open apperception, by allowing us to show how we contextualise our interpretations (showing where they come from) so that we can give an account of the patterns behind our conceptualisations (the ways in which we choose to describe our interpretation of experience). The focus on rational reflexivity in Chapter 3 is therefore on opening up the usually automatic process of apperception, to allow some light on the tightly linked and overlapping practices of contextualisation and conceptualisation. Doing so allows us to consider how a more deliberate engagement can hold these practices apart, at least to a degree, and so make space for a more honest account of our situated experience (Iszatt-White, Kempster \& Carroll, 2017).

The final aspect of reflexive practice is the relational level, which has many overlaps with embodied, emotional and rational aspects of reflexive practice (Adjepong, 2019; Ripamonti, Galuppo, Gorli, Scaratti \& Cunliffe, 2017). In addition, at the relational level there can be self-reflexive, interpersonal and collective conceptualisations, involving a complex choreography of moving between and relying on the self and others (Nicholls, 2009). However, it is the engagement between the self and the other, with the intent to support the possibility of learning and the development of a shared horizon of understanding, which is key (Hibbert, Beech \& Siedlok, 2017; Hibbert, Sillince, Diefenbach $\&$ Cunliffe, 2014). These possibilities can be enacted in different ways through dialogue (Hibbert, Beech \& Siedlok, 2017; Simon, 2013), the use of media as a common focus (Ajjawi, Hilder, Noble, Teodorczuk \& Billett, 2020), or the juxtaposition of different interpretive frames (Keevers \& Treleaven, 2011).

Whether connections are established through dialogue, transitional objects or other forms of interaction, learning and change can follow (Bissett \& Saunders, 2015). This involves a letting go (at least for a time) of one's own interpretive authority, in order to receive new insights from the other, which 
needs to be followed by resolution through dialogue until the partners in the exchange believe they have established a shared interpretive horizon (Hibbert, Sillince, Diefenbach \& Cunliffe, 2014; Rhodes \& Carlsen, 2018). The practices of reception and resolution that are intrinsic to relational reflexive practice are important in helping to establish enlarged understandings. These insights are richer and deeper because, through dialogue, they connect to and reveal something of the 'hinterland' of each partner's understanding (Lupu, Spence \& Empson, 2018).

It is important to emphasise that, like reflexivity in general, all of the levels of reflexivity - embodied, emotional, rational and relational - can be more or less 'automatic'. We are always adapting to experience whether it affects us through our bodies, emotions, thoughts or relationships. But an awareness of what is going on at these levels lets us interrupt the automatic processes, in order to give an enriched account of our interpretations and choices, which is important for everyday reflexive practice and essential for interpretive research.

\subsection{APPLYING REFLEXIVE PRACTICES TO RESEARCH PROJECTS}

Chapter 4 considers how everyday reflexive practices can have a role across the full duration of a research project, stretching from the initial motivation to engage in a study to the processes of writing and revision on the way to producing published accounts of the research. The chapter describes what might be considered one kind of 'ideal type' of interpretive research process, that proceeds through clear steps in a more-or-less linear way. While lived-out experience of research projects is often more disordered and a lot less predictable, all projects tend to involve arrangements of the steps or phases that are set out in Chapter 4.

The 'ideal type' or organising framework for a research process that I set out in the chapter involves seven research phases or activities. First, I describe the initial characterisation of the research idea and the commitment that we develop before any formal project is underway. I explain how this can be either 'hot' or 'cold' - driven from emotional reflexive practice and deep personal engagement with the research question, or from an analytical focus on literature emphasising rational reflexive practice, tempered by relational reflexive practice to challenge the research ideas that we develop.

Second, I explore the grounding of a potential project in literature to give it shape and provide a clear research focus. There are a range of skills deployed in assembling and working with literature, but underpinning these is a pattern of rational reflexive practice involving apperception - interpreting new ideas in the context of what we already know, to be able to conceptualise our own 
view of the field - that we can engage with in a deliberate way. I also argue that relational reflexive practice has a role in shaping how a project is grounded in literature, through providing different views on our appropriation of literature, such that we can develop plausible generative speculations about where the planned research should focus.

The third element is concerned with the identification of the context(s) in which a study can be conducted. I argue that 'hot motivations' and research initiated by emotional perceptions will likely lead directly to the situations that led to the heat as the most appropriate contexts for the study. In contrast, 'cold motivations' are likely to lead to rationally reflexive practice to guide the selection of research site(s), through determining fit with our established contextualisation of the field.

In the fourth element, choices about data - how it is identified, delimited and captured - are considered. There are potential arguments about the role of embodiment and emotions in leading us to data, especially in field research. In response, I describe how relational reflexive practice helps us to establish spatial boundaries for data collection, while rational reflexive practice can help us to identify the temporal limits.

Approaches to analysis are discussed in the fifth part of the chapter, with an eye on how we develop meaningful insights from data or empirical material. I focus on appropriate forms for arranging and reporting data that includes observations developed (in whole or part) through embodied and emotional reflexive practice, and consider how relational and rational reflexive practices can help us to ensure that the accounts of our data that we craft can resonate with others as authentic views on the research context(s).

In the sixth element I explore the process of reconnecting to literature as we seek to show how meaningful insights, developed from data, can take the academic conversation in a new direction. I explain how this is a complex interplay between our own rational reflexive practice and relational reflexive practice in which we treat authors, through their texts, as partners in a generative conversation about our work. Through this conversational mode of engagement, that allows for a 'fusion of horizons' (Gadamer, 1998; Hibbert, Beech \& Siedlok, 2017), the possibility of shared understanding in relation to our intellectual contribution is developed.

The final element of the research process that I consider is the necessity of engaging in and reacting to debate as our work is challenged and reshaped during dissemination and publication processes. As with the previous element, I see this as another complex interplay between our own rational reflexive practice and relational reflexive practice, this time with reviewers, editors and perhaps audiences during conference presentations or workshops. However, I also discuss how it is difficult to avoid some embodied and emotional engagement during this process, especially if it proves to be challenging. I do 
not think that is necessarily a bad thing, and we may be right in some cases to trust how we feel about our work, rather than what others say about it.

The discussions about the role of reflexive practices in research processes, as set out above, cover pretty much every aspect other than ethical review procedures - those are matters that need to be addressed on an institutional level, in most cases since most have their own specific frameworks. Despite this broad scope, it is important to emphasise that I am not seeking to provide a comprehensive guide to qualitative research, or to argue for a particular style of interpretive research or to describe in detail a particular method (as I have done with colleagues elsewhere: see, for example, Hibbert, Sillince, Diefenbach \& Cunliffe, 2014). Instead, my aim is simply to show the role that reflexive practices can and should have in each of these processes. The aim is therefore to help readers consider how reflexive practices might be useful within their own research approach, especially if they are required to account for the choices that they make in particular projects.

While Chapter 4 emphasises the role of particular reflexive practices in different research activities or phases, it is important to note that all of the types of reflexive practice are potentially active at any time, but they may have more-or-less salience for the particular activities on which we are seeking to focus from moment to moment. The reflexive practices will also vary in relation to the nature of particular projects, and the seven principal activities of the 'ideal type' of research process may be combined and blended in different ways. To begin to explore some of the potential variations, Chapter 4 is followed by two case study chapters.

\subsection{PERSPECTIVES: VIEWS ON REFLEXIVE PRACTICE IN RESEARCH CASE STUDIES}

In Chapters 5 and 6, I look at my own lived experience of reflexive practice through two case studies. In each of these chapters, I use the framework set out in Chapter 4 to describe the study, but with variations to reflect the different shape of each study. It is important to point out at this stage that the cases were selected to provide as much variation as possible, within the scope of my career, but I have always focussed on interpretive research. With that in mind I selected my doctoral research project from many years ago, together with a collaborative research project that was approaching publication at the same time that this book was on the way to completion.

The exploration of my doctoral research in Chapter 5 presented me with some challenges. The first and most significant of these challenges was the need to 'retro-fit' my current understanding of reflexivity and reflexive practice on to a time when my engagement with those ideas was much less developed. Given the need to engage with case material intimately in order to 
comment on reflexive practice - with an awareness of embodied, emotional, rational and relational levels - I have some concerns about the possibility of 'getting in touch with the experience' after a great deal of time. However, as later work with colleagues has shown (Hibbert, Beech, Callagher \& Siedlok, 2021) very strong emotional perceptions tend to persist, and these helped to pull me back in to the experience of that time. So, while it would not have been possible for me to write an account of my research in the same way at the time it was being conducted, I believe that I have rendered an authentic account based on memory, research notes, draft writings and various other items of research documentation.

I considered that my doctoral research might be a useful case study for some of the readers of this book, who may themselves be researching their thesis, but more importantly it provides good examples of four challenges that are more general. First, in doctoral research studies we are usually expected to focus on supporting the generalisability of our insights and this reflexive practice can be focussed on that objective, in which we try to defend rather than own our interpretations of data, and that challenge is often faced in publication processes for other kinds of research project too. Second, research projects are usually imprecise and imperfect, with occasional changes of direction and missed opportunities (in general, and in relation to reflexive practice) and my doctoral research provides a good example of that normal level of messiness. Third, I hope to make this book useful for a wide range of researchers within the interpretive tradition, and since my research was focussed on widely applied social theory in multiple regional, national and international network contexts, it provides a lot of possibilities for connection across a range of disciplines. Fourth, while my doctoral research was based on data collected through a fairly common approach to participant observation, it had an unusual structure and a non-standard approach to analysis. Since accounting for the structure and methodology of the study are key issues in formal doctoral examinations and studies on the way to publication, my hope is that the account of how I wrestled with these issues in my research may resonate with and be useful to others.

The conclusion I reach from the consideration of my doctoral work is that reflexive practices do not need, necessarily, to be understood and named according to my scheme (or any other) in order to go on. However, I also conclude that having a way to recognise and name the reflexive practices in play does help us to be aware of them, even when we are using memory and documentary traces to try to retrieve insights long after the study has been completed. Often the need to demonstrate and give an account of our research reflexivity becomes clear later in the study, after we have rushed ahead with the research and forgotten some of the usual good practices (such as keeping a research diary) that would provide the basis for a contemporaneous account. However, with an appropriate framework of reflexive practices to shape a ret- 
rospective description, it is possible to give an effective account of reflexivity in the research process, even if the benefits of a more informed, aware, and contemporaneous engagement have been missed.

I turn to the discussion of a collaborative research project in Chapter 6, where the intention was to maximise the authenticity and relevance of the research account, with generalisability approached more tentatively through theorisation. The focal study was the most recent (at the time of writing) in a series of studies using a specific, relationally reflexive approach (Hibbert, Sillince, Diefenbach \& Cunliffe, 2014). I had worked for some time, with a group of friends, using a collaborative autoethnographic approach that allowed us to take roles as both researchers and participants. This approach allowed us to use our own experiences as the basis of research, and to be able to account for those experiences intimately on all reflexive levels - embodied, emotional, rational and relational - and so to be fully present in the study with significant control over our authentic voices.

The focal project in Chapter 6 arose from caring conversation within the group of friends, discussing the impact of negative emotional experiences on us during our academic careers. We felt that was a potentially useful topic for a research study that could focus on challenges for learning and leadership when facing such challenging emotional experiences, and that, based on wider conversations, the characterisations of these challenges and insights and ideas about how to address them could resonate with others. I focus on this study for two main reasons. The first reason is that it provides a contrast to the isolated, liminal and disempowered condition of doctoral research explored in Chapter 5. As a group of established academic staff, we had considerable freedom to decide what topics were of interest to us, and how to go about researching them. While relatively unusual approaches carry more risk when it comes to seeking publication, at our established career stages we could accommodate some risks within our portfolio. Our approach might be a more difficult 'sell' to a doctoral supervisor or committee in some contexts, although there are an increasing number of research groups and schools that accommodate this kind of work. The second and main reason for focussing on a collaborative autoethnographic project in Chapter 6 is that it provides a case in which reflexive practice was 'baked in' or intrinsic to the progress of the research. It would not have been possible to present authentic, resonant accounts as the basis of our insights if the group did not have both a good understanding of reflexivity and a commitment to reflexive practice.

The conclusions reached from the examination of a collaborative autoethnography in Chapter 6 focus on the influence of a commitment to a relationally reflexive method. That commitment led us to enlarge our circle of relational reflexive practice to incorporate external voices, and value internal voices in new ways. Published authors, engaged through their texts, were treated as 
trusted partners from whom we could actively receive ideas, along with critical voices that challenged our horizons of understanding. The internal conversation in our group provided a generative space for reflexive practice, helping us to operationalise our approach and record it authentically.

Across both case studies, in Chapters 5 and 6, there were also some common lessons and a number of other detailed insights. These chapters also provided the basis for re-approaching the theoretical material in the earlier chapters, in order to identify some of the key principles for 'how to be a reflexive researcher', while also identifying some opportunities for further work.

\subsection{INTEGRATION: ANSWERING SOME QUESTIONS, RAISING NEW ISSUES}

In Chapter 7, the concluding chapter of this book, I set out the key points that I have derived from my engagement with theory and experience in the realms of reflexivity and reflexive practice. In this section of the introduction, I therefore offer a summary of some of the main points set out in that chapter.

I conclude that the approach to reflexive practice that I develop is similar to established approaches, but self-reflexivity is given the primary position. It is from that perspective that other kinds of reflexivity are considered, through looking at the self (embodied and emotional reflexive practice) and looking from the self (rational and relational reflexive practice) to support critical engagement. I argue that this does not lead to an instrumental approach. Instead, it leads to an acceptance that we can go on, aware of our incompleteness and constraints but still struggling against these limits, without descending into a spiral of doubt that comes from radical reflexivity (Cunliffe, 2003; Cutcher, Hardy, Riach \& Thomas, 2020).

In addition, I argue that my approach is also novel in its focus on time, through establishing the differences and connections between everyday future-oriented, adaptive reflexivity and the past-oriented, re-interpretive approach to reflexivity often associated with research projects. Bearing those temporal forms in mind, being a reflexive researcher entails understanding both the inevitably of reflexivity in our adaptation to experience and the choices we make (Archer, 2007), together with the possibilities for a greater degree of awareness in our reflexive practice. Those understandings also allow us to consider how more deliberate and aware forms of reflexive practice are accommodated (perhaps within groups) and how reflexive insights are captured (through simple tools such as research diaries and notes). However, the case studies (Chapters 5 and 6) also show that even if our awareness of reflexive practice is less than ideal during a study - and there may be many reasons for that - then it is possible to recover some insights much later, especially when intense emotional perceptions anchor our experiences (Hibbert, 
Beech, Callagher \& Siedlok, 2021). It is important, though, not to suggest that we can strip away interpretations in this way and get back to the 'facts' in past research projects. The facts (if there are such) are always at an unapproachable distance; it is interpretation all the way down (Gadamer, 1998; Hibbert \& Huxham, 2010, 2011). However, a return to reflexive practice after the events can suggest other interpretations than those reached at the time, which may feel more authentic to ourselves and others. Overall, I argue for an integrated perspective on reflexive practice that brings embodied, emotional, rational and relational levels into a pattern moving between the future and the past, asking "what I should do next?" in the moments and months of our studies, while also asking "how did I come to make those choices?", in some cases long after the research has been concluded. This dual perspective brings everyday life and research practice into the same frame, constituting a scholarly way of life.

It is to be expected that a study of reflexive practice will lead to new issues and opportunities. You will be likely to form your own opinion on the questions that have arisen as you engage with this book from earlier chapters, but my personal perspective suggests two areas that present interesting opportunities for further study: the impact of personal health challenges on reflexive practice; and how reflexive practice is affected by institutional constraints.

A key example of personal health challenge that I focus on in Chapter 7 is mental health, and in particular anxiety and depression. This is an important and timely focus, given the long-established mental health crisis (Ehrenberg, 2009) and evidence of a particular problem in academia (Gorczynski, 2018). In addition to which, these are the health challenges with which I am most familiar and can connect with most authentically. Like any medical conditions, anxiety and depression impact on the practicalities and risks of conducting a study, but can also provide challenges in relation to what scholarly communities can accept as legitimately felt in the process of research and allow to be authentically recorded in a reflexive account (Todd, 2020).

A consideration of situational pressures and institutional constraints that have an effect on the possibilities for reflexive practice connects with approaches to critical reflexivity (see Chapter 2 ). A critically reflexive perspective focusses on the social constructions of tradition and ideology that shape our interpretive practice, in order to challenge the unquestioned norms that we reproduce in this way (Aronowitz, Deener, Keene, Schnittker \& Tach, 2015; Hibbert, Beech \& Siedlok, 2017; Hibbert, Coupland \& MacIntosh, 2010; Hibbert \& Huxham, 2010, 2011). I connect such objectives with engagement in rational and relational reflexive practice. This engagement helps to highlight how power differentials limit the disempowered person's ability to say what they experience through critical engagement and also undermine the empowered person's ability to see what the critical lens might reveal. 
My overall conclusion, having staked a claim to contribute to ongoing debates, is that the answer to 'how to be a reflexive researcher' involves: taking a theoretical position; becoming familiar with reflexive practices; developing honesty about our abilities and constraints; and being responsible. In the chapters that follow, I hope to lead you to the same conclusion; or at least, for us to end up within the same shared horizon of understanding, where relational reflexive practice can help us both to learn when opportunities arise.

\section{Dialogue}

Each chapter of this book ends with a direct invitation to you, usually through questions that mirror how I would start a conversation about the ideas discussed. Some readers find this helpful, but it is not essential to the flow of the book. For now:

1. I open each chapter with a personal reflection, sometimes serious and sometimes less so. I think it is necessary to reveal something of yourself in order to discuss reflexivity authentically. What are your views about that?

2. I argue that a scholarly way of life brings everyday reflexive practice and reflexivity in research studies into the same frame. How does this relate to your experience, and with what consequences? 